\title{
Zika virus disease: a current review of the literature
}

\author{
Muhammad Atif $^{1} \cdot$ Muhammad Azeem $^{1} \cdot$ Muhammad Rehan Sarwar $^{1} \cdot$ \\ Arslan Bashir ${ }^{1}$
}

Received: 13 June 2016 / Accepted: 2 August 2016 / Published online: 10 August 2016

(C) Springer-Verlag Berlin Heidelberg 2016

\begin{abstract}
Background The massive pandemic of Zika virus (ZIKV) infection is spreading through South America, Central America, the Caribbean, and possibly the USA. It is the most recent of four surprising appearances of imperative arthropod-borne viral illnesses in the Western Hemisphere over the preceding 20 years.

Objective The objective of this narrative review is to summarize the existing knowledge about the epidemiology, transmission, clinical manifestations, complications, replication, pathogenesis, diagnosis, and treatment and prevention of ZIKV infection.

Methods We used electronic databases to identify relevant published data regarding ZIKV in BOOLEAN and MeSH searches.

Conclusion This review concludes that the ZIKV predominantly circulates in arboreal mosquitoes (e.g., Aedes africanus) and wild primates. It rarely causes severe infection in humans, even in extremely enzootic regions. Currently, we do not have any efficacious drugs against ZIKV infection. However, there are virus-specific therapeutic targets, which may lead to the development of targeted anti-ZIKV drugs.
\end{abstract}

Muhammad Rehan Sarwar

rehansarwaralvi@gmail.com

Muhammad Atif

pharmacist_atif@yahoo.com; muhammad.atif@iub.edu.pk

Muhammad Azeem

azeem634@hotmail.com

Arslan Bashir

arslanbashir41@gmail.com

1 Department of Pharmacy, The Islamia University

of Bahawalpur, Punjab, Pakistan
Keywords Zika virus · Zika fever · Mosquitoes · Epidemiology $\cdot$ Clinical manifestations · Pathogenesis . Treatment
Abbreviations
ZIKV Zika virus
dsRNA Double-stranded RNA
ER Endoplasmic reticulum
GBS Guillain-Barré syndrome
mRNA Messenger RNA
PHEIC Public Health Emergency of International Concern

RT-PCR Reverse transcription polymerase chain reaction

\section{Introduction}

There is a strong relationship between infectious diseases (IDs) and poverty in that they both aggravate each other. Numerous studies have reported that the incidence rates of IDs are highest in areas where poverty is at its peak [1,2]. This relationship has also been stated in the Global Report for Research on Infectious Diseases of Poverty [3]. Furthermore, several IDs, such as malaria, dengue and tuberculosis, influence the lives of marginalized people living in developing regions, and these diseases remain uncontrolled [4]. Similarly, Zika virus (ZIKV) disease has rapidly increased and is closely associated with other arthropodborne diseases of poverty, such as dengue and chikungunya.

ZIKV is an RNA virus (non-segmented positive-sense RNA genome) that belongs to the Flaviviridae family and Flavivirus genus. The virus is approximately $50 \mathrm{~nm}$ in diameter and enveloped and spherical, with an icosahedrallike arrangement of surface proteins. It is named as "Zika Forest" and is located near Kampala, Uganda. Over the past 
few months, it has rapidly emerged in the Western Hemisphere [5]. This virus is similar to other member viruses of the family Flaviviridae, including yellow fever virus, dengue virus and West Nile virus, which cause febrile illness together with rashes. It also shares similar characteristics with the Spondweni virus [6].

ZIKV is transmitted to humans through the bite of daytime-active Aedes mosquitoes; however, infection risk through sexual activity and blood transfusions also exists [7-9]. Phylogenetic analyses of ZIKV suggest two important lineages, Asian and African, originating from a single ancestor, most likely in Uganda [7]. The possible vectors of Aedes species include Aedes polynesiensis and Aedes aegypti, identified in French Polynesia, and Aedes hesilli, identified in Yap [8, 10, 11]. Aedes albopictus and A. aegypti exist in many states of America, including various parts of the south-central and south-eastern USA and Hawaii $[5,8]$.

The RNA of the virion is infectious and acts as viral messenger RNA (mRNA) and viral genome. The genome is translated as a polyprotein with a length of 3419 amino acids and is processed co- and post-translationally by both host and viral proteases [12]. The ZIKV reproductive cycle begins with the attachment of the virion to the cell membrane of the host via an envelope protein that encourages endocytosis. After endocytosis, the viral membrane fuses with the endosomal membrane, and the single-stranded RNA (ssRNA) is discharged into the host cell cytoplasm. Then, translation begins and a polyprotein is cleaved, which is involved in the formation of all structural and nonstructural proteins. Replication occurs during the next step, which occurs in the cytoplasmic viral factories of the endoplasmic reticulum (ER), producing double-stranded RNA (dsRNA). This dsRNA undergoes transcription to form additional ssRNAs which assemble within the ER to form new virions. These virions are then transferred to the Golgi apparatus and are ultimately released into the intracellular spaces, where they cause infection of new cells [13].

A close resemblance exists among the clinical presentations of ZIKV, chikungunya and dengue, which are characterized by headache, fever, maculopapular rash, myalgia, arthralgia, and an array of complex signs and symptoms that restrict differential diagnosis. Although ZIKV infection is in most cases self-limiting or even unapparent, with a small risk of complications, some patients have developed neurologic symptoms and Guillain-Barré syndrome (GBS) in Brazil and French Polynesia [14, 15].

The objective of this narrative review is to present existing knowledge about the epidemiology, transmission, clinical manifestations, complications, replication, pathogenesis, diagnosis, treatment and prevention of ZIKV infection.

\section{Search strategy}

We searched PubMed, ScienceDirect and Google Scholar with the following keywords: "Zika virus", "Zika fever", "Epidemiology", "Transmission", "Clinical manifestations", "Replication", "Diagnosis", "Treatment", "Prevention" and "Vaccines" in several combinations in BOOLEAN and MeSH searches. The search covered the period from 2007 to July 2016.

The references of selected papers were also screened to identify relevant literature, and review articles were also cited when applicable. Due to the limited data published in scientific journals, we also explored the databases of leading organizations, such as the Centers for Disease Control and Prevention, World Health Organization (WHO) and Pan American Health Organization (PAHO).

\section{Epidemiology}

ZIKV (strain MR 766) was first isolated in April 1947 from a rhesus macaque monkey, which was used as a research animal by scientists of the Yellow Fever Research Institute, located in Zika Forest, near Lake Victoria, Uganda [16]. These scientists named this filterable transmissible agent "Zika Virus" in 1948 [17]. In January 1948, this virus was also isolated from Aedes africanus at the same site. The very first human cases were reported in 1952 in Tanzania and Uganda [12].

Between 1951 and 1981, evidence of human ZIKV infections was confirmed in various countries in Africa, including Sierra Leone, the Central African Republic, Gabon, Uganda, Tanzania and Egypt, as well as different regions of Asia, such as Malaysia, India, Pakistan, the Philippines, Indonesia, Vietnam and Thailand. Only 14 human cases were identified until 2007 and these originated in Southeast Asia and Africa [17].

After its emergence (during the first 60 years), ZIKV infection showed a geographical restriction [11, 18]. Outside of Asia and Africa, the first outbreak of ZIKV infection was reported on the island of Yap in the Federated States of Micronesia in April 2007. The disease was manifested as conjunctivitis, rash and arthralgia and was initially diagnosed as chikungunya, dengue or Ross River disease. Later, specimens obtained from suspected patients were revealed to contain the RNA of ZIKV. There were approximately 49 confirmed and 59 unconfirmed cases, with no hospitalizations or deaths [11]. More than $70 \%$ of the Yap children having an age of 3 years developed infection within 4 months [11]. In this outbreak, the attack rate was 14.6 per 1000 inhabitants (range 3.5-21.5 per 1000 inhabitants). 
In French Polynesia, ZIKV was first identified in October 2013. Until December 2013, it was assumed to account for approximately 19,000 cases of dengue-like syndrome. Approximately, 30,000 humans (about $11 \%$ of the total French Polynesian population) developed ZIKV infection [18-21]. This French Polynesian virus was closely related to the virus isolated in Cambodia in 2010 [10]. Subsequently, in 2014, ZIKV was also detected in Easter Island (Chile), the Cook Islands and New Caledonia [22]. Phylogenetic analysis showed that the NS5 gene sequence of the Chilean strains had $99.8 \%$ nucleotide and $100 \%$ amino acid similarity to the French Polynesian strains [23]. This epidemic continuously expanded and caused indigenous human cases in numerous Latin American countries in the subsequent 2 years.

Brazil is the most adversely affected country of the Latin American region with an approximately 500,000-1,500,000 ZIKV cases since March 2015 [24]. Numerous cases of dengue-like syndrome in Natal, in the state of Rio Grande do Norte, Brazil, were confirmed as ZIKV infection, which were diagnosed using reverse transcription polymerase chain reaction (RT-PCR). Afterward, numerous outbreaks occurred in different states of Brazil, Colombia, Mexico, Guatemala, Paraguay, El Salvador, Bonaire, Samoa, Trinidad and Tobago, Aruba, Sint Maarten, Argentina, Venezuela, etc. and subsequently reached the USA. A close phylogenetic relationship between Asian and Oceanic strains and South American strains of ZIKV may be associated with the introduction of ZIKV in Brazil by the participants from the Oceanic countries for the Va'a World Sprint Championship or Asian travelers during the FIFA World Cup [21, 25-27]. In 2015, global warming and climate changes in association with El Niño in North and eastern South America might have further accelerated the spread of Aedes mosquitoes and ZIKV in Brazil [28]. At present, more than 30 countries in Asia, Africa, Oceania, Micronesia and South America have reported indigenous human ZIKV cases [29]. The travel-related cases from epidemic and endemic regions were also reported in North America, Australia, Europe and Japan [30-37]. As of 27th July 2016, a total of 50 territories and countries in the Americas have reported ZIKV infections. According to most recent data submitted to ArboNET, a total of 1658 ZIKV cases have been reported in the USA. Out of these, 1657 were travel associated. Similarly, a total of 4750 ZIKV cases have been reported in the US territories. Out of these, only 21 were travel associated, while the remaining cases were locally acquired [38]. The Asian lineage is responsible for all ZIKV outbreaks in the Americas and the Pacific [5].

\section{Transmission}

An aggravating factor for the transmission of mosquitoborne diseases is poverty [39-41]. Mosquito-borne viruses, such as ZIKV, may hit communities with poor infrastructure and sanitation more frequently. Overcrowding, lack of access to piped water, presence of stagnant water, household sewage, streets strewn with rubbish and swarms of mosquitoes around the trash give rise to the perfect set of conditions for the augmented transmission of ZIKV in poor communities. The recent outbreak of ZIKV disease in Brazil clearly favors the areas of poverty. Currently, approximately 1.5 million cases of ZIKV disease have been reported in Brazil, with the overwhelming majority of cases occurring in the poorer north-eastern states of Pernambuco, Bahia and Paraiba [42, 43]. On February 1, 2016, WHO declared mosquito-borne ZIKV disease a public health emergency of international concern (PHEIC), following reports from the Brazilian Ministry of Health and PAHO $[42,44]$. Because there is a debate regarding the relationship between poverty and ZIKV transmission, ZIKV disease may not be a condition that affects only poor people because vector mosquitoes can breed in stagnant water, even in developed regions of the world, and can bite anyone. The current episode of ZIKV disease in the Americas [43] adds weight to this argument.

ZIKV is mainly transmitted to humans through mosquitos. The most important and common vectors for ZIKV are Aedes mosquitoes; however, some Anopheles, Eretmapodites, Culex and Mansonia species have also been purported as potential vectors [45-47]. In Asia and Africa, based on serological and virological evidences of ZIKV, the most probable non-human animal reservoirs are Cercopithecus aethiops, Macaca mulatta, Cercopithecus denti, Cercopithecus ascanius schmidti, Chlorocebus sabaeus, Lophocebus albigena, Pongo pygmaeus, Erythrocebus patas and Colobus abyssinicus, and other mammals such as elephants, zebras and rodents [47-49].

Similar to other arboviruses, the transmission of ZIKV through blood transfusion is also possible. This is important in endemic areas or other regions where the bloodrelated products may be gained from ZIKV-infected travelers returning directly from endemic areas. During the epidemic, the ZIKV RNA was found in $2.8 \%$ of the blood donors in French Polynesia [50]. There is a high probability of ZIKV transmission through sexual route, specifically in patients of hematospermia having RNA and infectious viral particles in the semen [51]. No other arbovirus has shown any association with hematospermia or is found in the semen [9]. Unintentional sexual transmission of ZIKV to the female partner and subsequently to the fetus may result in awful congenital anomalies among the newborns.

Transmission of ZIKV from mother to infant can occur in utero or perinatally $[8,52,53]$. Transmission of ZIKV via breastfeeding has not yet been observed [8], although the transmission of other flaviviruses via this route has been described previously $[54,55]$. The other suspected routes 
of ZIKV transmission include monkey bite, mucocutaneous exposure, organ transplantation or hemodialysis [56, 57]. The risk of ZIKV infection among kidney recipients should also be considered if the donors are either residing in or returning from endemic regions, because the virus may be shed in the urine of the infected person for more than 30 days $[31,32,58]$. Due to occasional detection of viral RNA in saliva samples and nasopharyngeal swab, it is still unknown that ZIKV could be spread through respiratory droplets $[52,59]$.

\section{Clinical manifestations}

The incubation period of ZIKV is 3-12 days, and the illness caused in humans is usually mild [60]. Severe illness and case fatality rates are very low. Symptoms of the illness are generally relieved within 2-7 days, but ZIKV can be detected in the blood of an infected person even 1 week after cure. Upon first exposure, a person develops immunity and does not develop the disease again in the future [61].

\section{Adults}

Approximately, 20-25\% of infected individuals develop ZIKV disease [11]. Signs and symptoms include short-term and low-grade fever $\left(37.8-38.5^{\circ} \mathrm{C}\right)$ coupled with maculopapular and pruritic rashes, conjunctivitis (non-purulent) and arthralgia (particularly, the smaller joints of the feet and hands) $[62,63]$. The concurrent presence of two or more of these symptoms confirms ZIKV disease [64]. Other frequently described clinical signs associated with acute infection include headache, myalgia, hematospermia [51], asthenia, transient hearing loss [65], retro-orbital pain and subcutaneous bleeding [66]. There are additional rarely observed symptoms of ZIKV disease, including nausea, diarrhea, mucous membrane ulceration, abdominal pain, pruritus and thrombocytopenia [34].

The biochemical and hematological laboratory parameters are generally normal, though some patients may have transient and mild leucopenia, lymphopenia or activated lymphocytes, neutropenia, thrombocytopenia, monocytosis, increased erythrocyte sedimentation rate and raised serum levels of gamma-glutamyl transpeptidase, lactate dehydrogenase, aspartate aminotransferase, ferritin, fibrinogen and $\mathrm{C}$-reactive protein during the course of the viremic phase [20, 32, 34].

The ZIKV fever can be individualized from chikungunya and dengue fever by more noticeable edema in the extremities, low-grade thrombocytopenia, and less severe malaise and headache $[11,15]$. Furthermore, arthralgia in chikungunya fever is more severe than in ZIKV fever, and
Box 1 A comparison of the clinical features of the Zika virus with chikungunya and dengue [66]

\begin{tabular}{llll}
\hline Clinical features & Zika & Chikungunya & Dengue \\
\hline Maculopapular rash & +++ & ++ & + \\
Fever & ++ & +++ & +++ \\
Arthralgia & ++ & +++ & + \\
Conjunctivitis & ++ & - & - \\
Headache & + & ++ & ++ \\
Myalgia & + & + & ++ \\
Shock & - & - & + \\
Hemorrhage & - & - & ++ \\
\hline
\end{tabular}

in comparison to dengue fever ZIKV fever does not show hemorrhagic complications (Box 1) [11, 67]. The clinical characteristics of ZIKV disease in pregnant women are similar to those of non-pregnant women. Currently, no evidence indicates that pregnancy confers increased susceptibility to ZIKV infection or severe clinical symptoms [52, 68].

\section{Children}

Children can be infected with ZIKV through the intrauterine, intrapartum and postnatal routes $[8,53]$. Two different case reports described intrapartum transmission of ZIKV to infants and newborns, who developed infection within a few weeks of delivery. One newborn had no clinical signs or symptoms, whereas the other presented with diffuse rash and thrombocytopenia [52, 69]. To date, microcephaly has not been reported in any child who was infected with ZIKV at the time of birth [70]. The signs and symptoms of the disease in children are similar to those of infected adults [11, 69]; however, arthralgia is sometimes difficult to detect in children and can manifest as irritability, pain on palpation, walking with a limp, refusal to move or movement with great difficulty, or feeling pain while moving the affected joint [69]. No growth-related abnormalities have been reported in children who were born healthy and later developed ZIKV disease.

\section{Complications}

The major complications associated with ZIKV infection include congenital microcephaly and GBS.

\section{Intrauterine (congenital) infection}

The range of intrauterine consequences related to ZIKV infection and the determinants of fetal risks have not been fully explored. Although ZIKV infection has been 
confirmed in numerous cases of microcephaly [14, 71, 72], how many of these were actually caused by ZIKV infection has not been confirmed. Furthermore, the ZIKV genome has also been identified in pathological specimens of first trimester fetal miscarriages [14, 71], although it has not been confirmed whether ZIKV was the cause of these fetal losses.

Typical characteristics of intrauterine ZIKV infection include redundant scalp skin, low birth weight, polyhydramnios, anasarca and arthrogryposis. Neurological deformities include brainstem dysfunction, cerebral lesions, absence of swallowing and polymalformative syndromes [73]. Markedly, certain other characteristic features, for example chorioretinitis and hepatosplenomegaly, have not been reported [74]. Ultrasonographic examination shows intracranial calcifications specifically over the white matter of the frontal lobes, lentostriatal vessels, caudate, cerebellum, around the lateral and fourth ventricles, cerebral atrophy, dysgenesis of corpus callosum, enlarged cisterna magna, vermis and thalami, asymmetrical cerebral hemispheres, midline shift, severe unilateral ventriculomegaly and thinning of the parenchyma on the dilated side, brainstem and pons [68, 74].

The congenital anomalies or intrauterine death may occur in response to earlier infections during the first or even second trimesters $[14,75]$. As proposed by the preliminary data, the risk of congenital deformities and microcephaly is highest if ZIKV infection occurs in the first trimester [73]. In Brazil, out of the total 35 women having infants born with microcephaly, 57 and $14 \%$ had a rash during the first and second trimesters, respectively [74]. There is also a possibility that ZIKV infection occurring in later stages of pregnancy appears in a different way with less severe deformities, for example, sensorineural deafness, ophthalmological lesions, mental retardation or miscarriage [74]. Newborns with possible perinatal ZIKV transmission seem to have mild disease and favorable consequence [52]. Further studies should be conducted to define the spectrum of symptoms in various gestational stages of ZIKV infection.

In parallel to the current ZIKV outbreak in Brazil, many microcephaly cases have been noted in newborns. The affected cases have head circumferences $\geq 2$ standard deviations below the mean for sex and gestational age at birth [74]. During the period from March 2015 to February 2016, a greater than 20-fold increase in microcephaly cases was observed in Brazilian newborns compared to previous years [22]. A recent retrospective analysis from Brazil revealed 17 cases of central nervous system-related malformations among neonates [76].

Before 2007, no cases of birth defects and fetal complications were reported during the ZIKV outbreaks in Asia and Africa. Here, this question arises; if ZIKV was present in Asia and Africa for so many years, then why was its link with microcephaly not detected before and why has the epidemic hit Brazil and not, for instance, Africa? Several reasons might be accountable for this. First, in Africa, ZIKV remained in a sylvatic cycle largely involving monkeys and a number of Aedes mosquitoes [6, 77]. This was possibly because the African lineage strain of ZIKV was associated with low viremia in humans [77], whereas the Asian lineage strain of ZIKV, involved in current outbreaks (Pacific Islands and in South America), is spreading along long chains of human-to-human transmissions. Second, the differences between the genetic makeup of the African and Asian lineages and adaptive changes in the Brazilian strain might explain the recent emergence of ZIKV-associated complications in humans [78-80]. Third, microcephaly is a rare disease and has many causes [81] other than ZIKV. Therefore, during the initial spread of ZIKV in Asia and Africa, cases of ZIKV-associated microcephaly were not reported due to the presence of a number of other blaming factors.

\section{Pathogenesis of microcephaly}

Pathogenesis of microcephaly due to ZIKV infection is still unclear because of the limited experimental evidences. Recently, a few studies [79, 80, 82-85] have evidenced the pathogenic potential of Brazilian strain of ZIKV during the development of fetus in animal models. These studies concluded that ZIKV first infects the placenta and then the brain of fetus, where it preferentially infects neural progenitor cells and decreases their viability and growth as neurospheres through down-regulation of genes that are involved in cell and organ development, and up-regulation of genes that are involved in immune responses. This results in inhibited cellular proliferation and differentiation, neuronal apoptosis, thinning of the cortex and macroscopic features similar to microcephaly. Based on the results of the above stated studies [79, 80, 82-85], a causal link between ZIKV infection and microcephaly could be hypothesized.

\section{Guillain-Barré syndrome}

With regard to the current ZIKV outbreak, an unusual increase in GBS cases has been reported in the Americas [14]; however, a linear association has not yet been noted.

During the previous outbreak (2013-14) of ZIKV infection in French Polynesia, the association between ZIKV infection and GBS was analyzed in a case-control study. In this study, two control groups, including a group of 70 patients with ZIKV infection (no neurological complications) and a second group of 98 patients with non-febrile illnesses (matched for residence, age and sex) and 42 GBS cases (test group) were included in the analysis. ZIKV IgM 
was positive in $93 \%$ of GBS cases versus $17 \%$ of patients in the second control group. In less than $50 \%$ of these GBS cases, anti-glycolipid IgG antibodies were detected, raising the probability of direct viral neurotoxicity. Symptoms of ZIKV infection were observed in $88 \%$ of GBS patients. All GBS cases were administered immune globulin intravenously, and intensive and respiratory care was required by 38 and $29 \%$ of cases, respectively. Consequently, there was a $100 \%$ survival rate. The estimated incidence of GBS was 0.24 cases per $1000 \mathrm{ZIKV}$ infections during the outbreak [86].

\section{Pathogenesis}

On biting an infected patient, the Aedes mosquito ingests a blood meal containing ZIKV. Similar to other flaviviruses, ZIKV replicates in the midgut and salivary glands. After an extrinsic incubation period of 5-10 days, ZIKV can be found in the mosquito's saliva which can cause human infection upon biting [87, 88]. Additionally, it can also be transmitted vertically from mother to child like other flaviviruses. When the infected saliva of the mosquito is inoculated into human skin, it can infect fibroblasts in the subcutaneous layer, epidermal keratinocytes and the Langerhans cells [89]. The fibroblasts and keratinocytes contain Tyro3, AXL and TIM-1 which can serve as receptors for ZIKV. DC-SIGN in Langerhans cells can also serve as receptors for virus entry [89]. The primary infection of skin fibroblasts with ZIKV is linked to the up-regulation with TLR3 mRNA expression and increased transcription of RIG-I and MDA5, which are well known innate immune responses to
RNA virus infections. This is followed by a greater expression of interferon-alpha and -beta, and their downstream pathways of immune activation. Both of the type I and type II interferons can restrain the viral load of infected cells. Since ZIKV has the capability to increase its replication by inducing autophagy in host cells, the viral load of the infected cells can also be decreased by autophagy inhibitors [90]. Infected cells of human skin explant show pyknotic nuclei, cytoplasmic vacuolation and edema in the stratum granulosum [89]. After replication in the local tissue cells and the regional lymph nodes, ZIKV may then spread from the bloodstream and lymphatics to other tissues and organs, including the central nervous system, myocardium, skeletal muscles, and likely to the fetus via placenta [91].

\section{Diagnosis}

\section{Direct viral diagnosis}

ZIKV infection can be diagnosed primarily by RT-PCR. The viremic period is believed to be small, as the virus can be detected in the blood from day 0 to 4 after the onset of symptoms. The time required for the recognition of viral RNA in blood may also depend on the viral load during the acute phase of the disease, because viremia decreases over time. A negative PCR result in blood collected 5-7 days after the onset of symptoms does not exclude the flavivirus infection. Therefore, serologic testing should be considered [92].

Various other specimens (for example, saliva and urine), at different time frames, may also be used for the detection

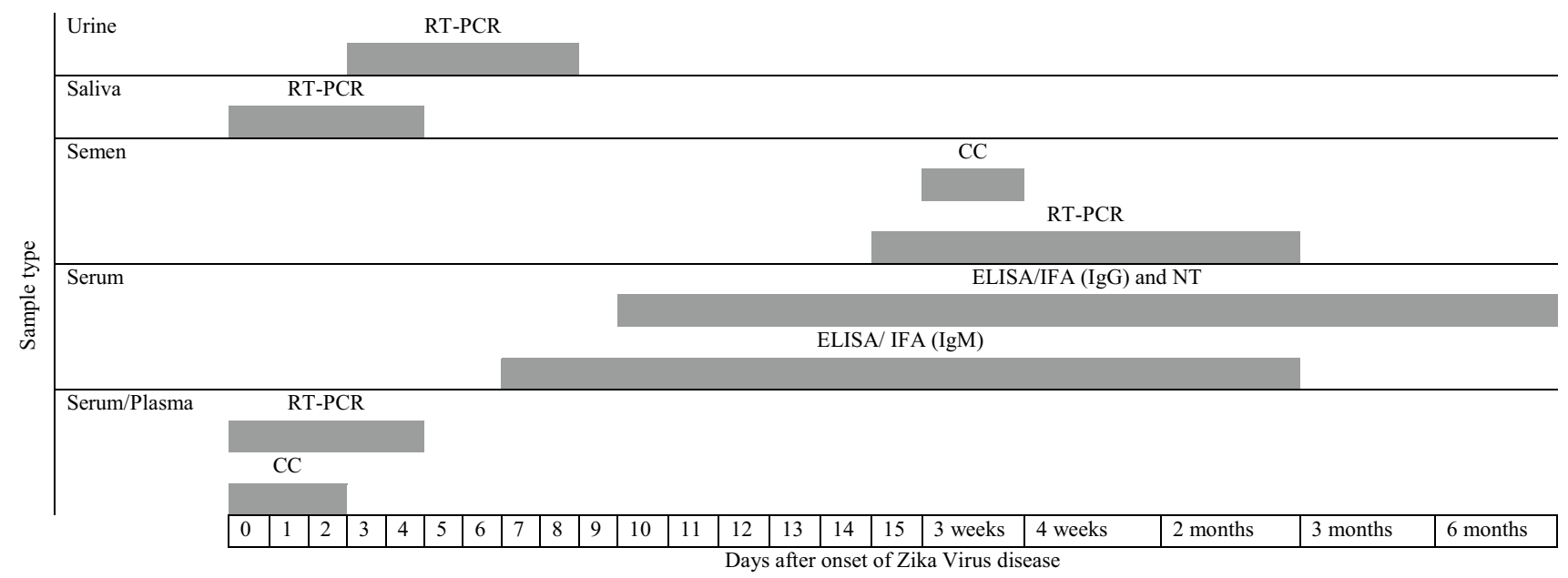

Fig. 1 An overview of the laboratory diagnosis showing optimal periods for detection of ZIKV infection in different samples through different techniques. $R T-P C R$ reverse transcription polymerase chain reaction; $C C$ cell culture; ELISA enzyme-linked immunosorbent assay; IFA immunofluorescent assay; $N T$ neutralization test. Note: optimal periods for the detection of ZIKV infection in other samples such as amniotic fluid, cerebrospinal fluid, joint fluid, bone marrow, placenta, skin biopsy, nasopharyngeal swabs and other tissues are not included in the above figure due to unavailability of detailed information 
of ZIKV RNA (Fig. 1). The detection period of ZIKV RNA in saliva (6-8 days after the onset of symptoms) is not considerably longer than the presence of RNA in blood. However, it is advantageous because of being non-invasive, and one study reported even higher sensitivity in testing [59]. Similar to other flaviviruses, urine may also be used to detect ZIKV RNA [93, 94]. In fact, ZIKV may stay in the urine and remain positive for a longer duration than in the serum $[51,58]$. Several studies have reported the detection of ZIKV RNA in urine more than 10 days after disease onset $[20,31,95,96]$. Still at this point, there is no validated data that suggests the replacement of blood with urine as a sample specimen $[20,31,96]$. A study has reported the time of stay of ZIKV in the semen of infected men for more than 3 weeks [51], while another study has reported ZIKV RNA in the semen for up to 62 days [97]. ZIKV detection can also be made in other specimens, for example cerebrospinal fluid, placenta and amniotic fluid $[14,71]$.

\section{Serological diagnosis}

Clinical signs and symptoms of ZIKV infection are nonspecific, therefore, requiring laboratory examinations for differential diagnosis. Serologic testing (i.e., enzymelinked immunosorbent assay or immunofluorescence assays) is used for the detection of ZIKV IgM antibodies from day 4 to 5 after the onset of symptoms. In general, the time duration for which the specific IgM antibodies for flaviviruses remain detectable is $2-3$ months, but sometimes for a longer period of time, while the specific IgG antibodies remain detectable for several months. At present, there is no validated commercial assay for ZIKV serological diagnosis. Therefore, serological confirmation should be performed in a laboratory with expertise in discriminating flaviviruses [92].

In countries that are most recently affected, other arboviruses are also present, specially chikungunya and dengue. These viruses may interfere with the serologic testing and can cause false-positive results for ZIKV infection. Therefore, positive results should be confirmed by the plaque reduction neutralization test. Virus neutralization tests are the most specific tests for flavivirus serology. A complicated diagnosis may indicate the presence of co-infection with chikungunya (potential) and dengue (proven) [64].

\section{Treatment strategy}

ZIKV illness is generally mild in nature, requiring no specific treatment. Infected patients should increase their fluid intake and rest for longer durations. The only pharmacological treatment is acetaminophen, which is used to alleviate symptoms of headache, fever and myalgia. Pruritus can be controlled with antihistamines, while fluid loss through vomiting and sweating should be corrected with adequate rehydration. Aspirin should not be used because of the risk of bleeding in patients with thrombocytopenia [5] and development of Reye's syndrome in children under 12 years of age. Due to the risk of severe hemorrhagic complications, nonsteroidal anti-inflammatory drugs are also contraindicated in cases where dengue and chikungunya infections cannot be assuredly excluded. Latent neurological complications, particularly GBS, should be diagnosed quickly to allow early utilization of plasmapheresis and/or intravenous immunoglobulins [91]. If convalescent-phase plasma therapy with neutralizing antibodies is being used for the treatment of severe ZIKV infection cases, then the risk of immune enhancement should also be considered [91].

The infected child and the family should be counseled by a multidisciplinary team consisting of clinical geneticists or dysmorphologists, pediatric neurologists, pharmacists, infectious disease specialists and other related specialists [98]. Long-term follow-up should also be offered to monitor functional, physical and intellectual progress of the child [98].

\section{Prevention}

The main vectors involved in the spread and transmission of dengue, chikungunya and Zika are a wide range of Aedes mosquitoes. Therefore, preventive measures begin with strategies intended to avoid mosquito contact. These strategies include drainage of mosquito breeding sites and use of insecticides and $N, N$-diethyltoluamide (DEET) or picaridin containing insect repellents.

Appropriate arrangements and sanitation campaigns on large scale should be organized to eradicate the breeding sites for mosquitoes in household as well as high-risk areas including construction sites, garbage collection points, and inappropriate car fields and dumping grounds. A minimum radius of $400 \mathrm{~m}$ of mosquito-free area should be maintained around higher population density areas, for example schools, churches, health-care facilities and transport terminals. The use of sprays should be considered to eliminate mosquitoes in areas where ZIKV cases have been detected. Travelers to or residents in the affected areas should spend maximum time indoor or use insect repellents while going outdoors. They should also use full sleeve shirts, long pants and if possible permethrin-treated clothes [98]. Registered insect repellents, including DEET, should be prepared in such concentrations that are safe for pregnant and lactating women (20\% DEET), and children (10\% DEET) aged $>2$ months [99]. The asymptomatically infected individuals 
returning from affected areas to non-affected areas should continue the use of insect repellents for a minimum of extra 14 days to avoid the local mosquitoes (previously non-infected) to obtain virus. By this strategy, the mosquito-human-mosquito ZIKV transmission triangle can be interrupted.

Specific measures are used to prevent the non-vectorborne transmission of ZIKV, for example universal nucleic acid testing of blood donors is recommended if a blood transfusion is to be made. Universal primers should also be considered that can detect various arboviruses simultaneously. Another important measure is to discontinue the blood donation temporarily during an outbreak. In non-endemic regions, a questionnaire should be answered by the blood donors to obtain their recent travel history to identify the potential carriers. Likewise, the donated organs, particularly kidneys, from persons with a recent travel history to affected areas should be examined for ZIKV, because the virus may exist in the genitourinary tract for an uncertain time duration [31, 32]. Safe sexual practices are also recommended to prevent the sexual transmission of ZIKV. Male partners returning from an infected area should use condom while having sex with their pregnant partners throughout the duration of pregnancy. There are also recommendations of some regional authorities for females to avoid pregnancy until an epidemic is over [100]. Pregnant females or those intending to be pregnant should avoid traveling to the ZIKV epidemic regions. In circumstances when travel is unavoidable, these individuals should strictly follow personal protective measures to avoid mosquito contact. Other less common routes of transmission such as mucocutaneous exposure and bites of infected primates should also be avoided by strictly complying with the infection control measures.

Although effective vaccines exist for different flaviviruses, no vaccine can prevent ZIKV infection [101, 102]. There is an immediate requirement for ZIKV vaccine. Some practical approaches are: attenuated chimeric vaccine (dengue vaccine employing the yellow fever vaccine backbone, presently in Phase III clinical trial), killed or live attenuated vaccine from human cell lines (as that of yellow fever and Japanese encephalitis vaccines) and DNA and recombinant protein vaccine [103].

\section{Conclusions}

ZIKV infection is a pandemic that is spreading throughout different parts of the world. It became the first major ID linked to human birth defects and created such a dire global situation that it was declared a PHEIC by WHO. Currently, what will happen in future regarding ZIKV epidemic is unpredictable. However, based on the worldwide spread of chikungunya and dengue over the last two decades, it may be assumed that ZIKV has the potential to show similar spread. Because of prior ignorance and a lack of appropriate research to detect the infectious agents and determine infection risks, currently we do not have any efficacious drugs against ZIKV infection. However, there exists virusspecific therapeutic targets, which may lead to the development of targeted anti-ZIKV therapeutic agents. Research preparedness is required on an immediate basis to improve mosquito control procedures and to develop point-of-care laboratory diagnostics, vaccines and antivirals that are appropriate to be used in pregnant women. It is therefore time to increase the level of integrated and timely research and improve our understanding of the complicated ecosystems in which the infectious agents of future pandemics are rapidly evolving.

\section{Compliance with ethical standards}

Conflict of interest The authors declare that they have no competing interests.

Funding No funding was involved in the preparation of this review or in the decision to submit it for publication.

\section{References}

1. Xia S, Allotey P, Reidpath DD, Yang P, Sheng HF, Zhou XN. Combating infectious diseases of poverty: a year on. Infect Dis Poverty. 2013;2:27. doi:10.1186/2049-9957-2-27.

2. Bhutta ZA, Salam RA, Das JK, Lassi ZS. Tackling the existing burden of infectious diseases in the developing world: existing gaps and the way forward. Infect Dis Poverty. 2014;3:28. doi:10.1186/2049-9957-3-28.

3. World Health Organization. Global report for research on infectious diseases of poverty 2012. Geneva, Switzerland: WHO; 2012.

4. Bergquist R, Whittaker M. Control of neglected tropical diseases in Asia Pacific: implications for health information priorities. Infect Dis Poverty. 2012;1:3. doi:10.1186/2049-9957-1-3.

5. Chen LH, Hamer DH. Zika virus: rapid spread in the Western hemisphere. Ann Intern Med. 2016;164:613-5. doi:10.7326/ M16-0150.

6. Faye O, Freire CC, Iamarino A, Faye O, de Oliveira JV, Diallo $\mathrm{M}$, et al. Molecular evolution of Zika virus during its emergence in the 20(th) century. PLoS Negl Trop Dis. 2014;8:e2636. doi:10.1371/journal.pntd.0002636.

7. Lanciotti RS, Kosoy OL, Laven JJ, Velez JO, Lambert AJ, Johnson AJ, et al. Genetic and serologic properties of Zika virus associated with an epidemic, Yap State, Micronesia, 2007. Emerg Infect Dis. 2008;14:1232-9. doi:10.3201/ eid1408.080287.

8. Hennessey M. Zika virus spreads to new areas-region of the Americas, May 2015-January 2016. MMWR Morb. Mortal. Wkly. Rep. 2016;65:1031-4.

9. Foy BD, Kobylinski KC, Chilson Foy JL, Blitvich BJ, Travassos da Rosa A, Haddow AD, et al. Probable non-vector-borne transmission of Zika virus, Colorado, USA. Emerg Infect Dis. 2011;17:880-2. doi:10.3201/eid1705.101939. 
10. Cao-Lormeau VM, Roche C, Teissier A, Robin E, Berry AL, Mallet HP, et al. Zika virus, French polynesia, South pacific, 2013. Emerg Infect Dis. 2014;20:1085-6. doi:10.3201/eid2006.140138.

11. Duffy MR, Chen TH, Hancock WT, Powers AM, Kool JL, Lanciotti RS, et al. Zika virus outbreak on Yap Island, Federated States of Micronesia. N Engl J Med. 2009;360:2536-43. doi:10.1056/NEJMoa0805715.

12. Haddow AD, Schuh AJ, Yasuda CY, Kasper MR, Heang V, Huy $\mathrm{R}$, et al. Genetic characterization of Zika virus strains: geographic expansion of the Asian lineage. PLoS Negl Trop Dis. 2012;6:e1477. doi:10.1371/journal.pntd.0001477.

13. MicrobeWiki. Reproductive Cycle of a Zika virus in a Host Cell. 2016. https://microbewiki.kenyon.edu/index.php/Zika_ virus\#cite_ref-g_5-1. Accessed 1 Mar 2016.

14. Mlakar J, Korva M, Tul N, Popovic M, Poljsak-Prijatelj M, Mraz J, et al. Zika virus associated with microcephaly. N Engl J Med. 2016;374:951-8. doi:10.1056/NEJMoa1600651.

15. Ioos S, Mallet HP, Goffart IL, Gauthier V, Cardoso T, Herida M. Current Zika virus epidemiology and recent epidemics. Medecine et maladies infectieuses. 2014;44:302-7. doi:10.1016/j. medmal.2014.04.008.

16. Dick GW, Kitchen SF, Haddow AJ. Zika virus. I. Isolations and serological specificity. Trans R Soc Trop Med Hyg. 1952;46:509-20.

17. Hayes EB. Zika virus outside Africa. Emerg Infect Dis. 2009;15:1347-50. doi:10.3201/eid1509.090442.

18. Derraik JG, Slaney D. Notes on Zika virus-an emerging pathogen now present in the South Pacific. Aust N Z J Public Health. 2015;39:5-7. doi:10.1111/1753-6405.12302.

19. Roth A, Mercier A, Lepers C, Hoy D, Duituturaga S, Benyon E, et al. Concurrent outbreaks of dengue, chikungunya and Zika virus infections-an unprecedented epidemic wave of mosquito-borne viruses in the Pacific 2012-2014. Euro Surveill. 2014;19:20929.

20. Dupont-Rouzeyrol M, O’Connor O, Calvez E, Daures M, John M, Grangeon JP, et al. Co-infection with Zika and dengue viruses in 2 patients, New Caledonia, 2014. Emerg Infect Dis. 2015;21:381-2. doi:10.3201/eid2102.141553.

21. Corsica F. Zika virus transmission from French Polynesia to Brazil. Emerg Infect Dis. 2015;21:1887.

22. Sexton DJ, Hirsch MS, Lockwood CJ, Edwards MS. Zika virus infection. Wolters Kluwer. 2016. http://www.uptodate.com/contents/zika-virus-infection. Accessed 1 Mar 2016.

23. Tognarelli J, Ulloa S, Villagra E, Lagos J, Aguayo C, Fasce R, et al. A report on the outbreak of Zika virus on Easter Island, South Pacific, 2014. Arch Virol. 2016;161:665-8.

24. Bogoch II, Brady OJ, Kraemer M, German M, Creatore MI, Kulkarni MA, et al. Anticipating the international spread of Zika virus from Brazil. Lancet (London, England). 2016;387:335-6.

25. Enfissi A, Codrington J, Roosblad J, Kazanji M, Rousset D. Zika virus genome from the Americas. Lancet. 2016;387:2278. doi:10.1016/S0140-6736(16)00003-9.

26. Salvador FS, Fujita DM. Entry routes for Zika virus in Brazil after 2014 world cup: new possibilities. Travel Med Infect Dis. 2016;14:49-51. doi:10.1016/j.tmaid.2015.10.004.

27. Marcondes CB, Ximenes MDF. Zika virus in Brazil and the danger of infestation by Aedes (Stegomyia) mosquitoes. Rev Soc Bras Med Trop. 2016;49:4-10. doi:10.1590/0037-8682-0220-2015.

28. Paz S, Semenza JC. El Nino and climate change-contributing factors in the dispersal of Zika virus in the Americas? Lancet. 2016;387:745. doi:10.1016/S0140-6736(16)00256-7.

29. Organization WH. Zika situation report-neurological syndrome and congenital anomalies, 5 February 2016. 2016.

30. Kwong JC, Druce JD, Leder K. Zika virus infection acquired during brief travel to Indonesia. Am J Trop Med Hyg. 2013;89:516-7. doi:10.4269/ajtmh.13-0029.
31. Fonseca K, Meatherall B, Zarra D, Drebot M, MacDonald J, Pabbaraju K, et al. First case of Zika virus infection in a returning Canadian traveler. Am J Trop Med Hyg. 2014;91:1035-8. doi:10.4269/ajtmh.14-0151.

32. Kutsuna S, Kato Y, Takasaki T, Moi M, Kotaki A, Uemura H, et al. Two cases of Zika fever imported from French Polynesia to Japan, December 2013 to January 2014 [corrected]. Euro Surveill. 2014;19:20683.

33. Tappe D, Rissland J, Gabriel M, Emmerich P, Günther S, Held $\mathrm{G}$, et al. First case of laboratory-confirmed Zika virus infection imported into Europe, November 2013. Euro Surveill. 2013;54:54.

34. Zammarchi L, Stella G, Mantella A, Bartolozzi D, Tappe D, Gunther S, et al. Zika virus infections imported to Italy: clinical, immunological and virological findings, and public health implications. J Clin Virol Off Publ Pan Am Soc Clin Virol. 2015;63:32-5. doi:10.1016/j.jcv.2014.12.005.

35. Summers DJ, Acosta RW, Acosta AM. Zika virus in an American recreational traveler. J Travel Med. 2015;22:338-40. doi:10.1111/jtm.12208.

36. Korhonen EM, Huhtamo E, Smura T, Kallio-Kokko H, Raassina $\mathrm{M}$, Vapalahti $\mathrm{O}$. Zika virus infection in a traveller returning from the Maldives, June 2015. Euro Surveill. 2016;21:30107. doi:10.2807/1560-7917.ES.2016.21.2.30107.

37. Duijster JW, Goorhuis A, van Genderen PJ, Visser LG, Koopmans MP, Reimerink JH, et al. Zika virus infection in 18 travellers returning from Surinam and the Dominican Republic, The Netherlands, November 2015-March. Infection. 2016;2016:16. doi:10.1007/s15010-016-0906-y.

38. Centers for Disease Control and Prevention. Zika virus disease in the United States, 2015-2016. 2016. http://www.cdc.gov/ zika/geo/united-states.html. Accessed 31 July 2016.

39. Reiter P. Climate change and mosquito-borne disease: knowing the horse before hitching the cart. Rev Sci Tech. 2008;27:383-98.

40. Butler CD. Infectious disease emergence and global change: thinking systemically in a shrinking world. Infect Dis Poverty. 2012;1:5. doi:10.1186/2049-9957-1-5.

41. Bai L, Morton LC, Liu Q. Climate change and mosquitoborne diseases in China: a review. Glob Health. 2013;9:10. doi:10.1186/1744-8603-9-10.

42. de Oliveira WK. Increase in reported prevalence of microcephaly in infants born to women living in areas with confirmed Zika virus transmission during the first trimester of pregnancy-Brazil, 2015. MMWR Morb Mortal Wkly Rep. 2016;65:242-7.

43. World Health Organization. Zika virus, Microcephaly and Guillain-Barre syndrome: situation report 7 April 2016. 2016. http://www.who.int/emergencies/zika-virus/situation-report/7april-2016/en/. Accessed 12 April 2016.

44. World Health Organization. Zika virus, Microcephaly and Guillain-Barre syndrome: situation report 19 February 2016. 2016. http://www.who.int/emergencies/zika-virus/situation-report/19february-2016/en/. Accessed 12 April 2016.

45. Diagne CT, Diallo D, Faye O, Ba Y, Faye O, Gaye A, et al. Potential of selected Senegalese Aedes spp. mosquitoes (Diptera: Culicidae) to transmit Zika virus. BMC Infect Dis. 2015;15:492. doi:10.1186/s12879-015-1231-2.

46. Diallo D, Sall AA, Diagne CT, Faye O, Faye O, Ba Y, et al. Zika virus emergence in mosquitoes in southeastern Senegal, 2011. PLoS One. 2014;9:e109442. doi:10.1371/journal. pone. 0109442.

47. Dick GW. Zika virus. II. Pathogenicity and physical properties. Trans R Soc Trop Med Hyg. 1952;46:521-34.

48. Kilbourn AM, Karesh WB, Wolfe ND, Bosi EJ, Cook RA, Andau M. Health evaluation of free-ranging and semi-captive orangutans (Pongo pygmaeus pygmaeus) in Sabah, Malaysia. J Wildl Dis. 2003;39:73-83. doi:10.7589/0090-3558-39.1.73. 
49. Wolfe ND, Kilbourn AM, Karesh WB, Rahman HA, Bosi EJ, Cropp BC, et al. Sylvatic transmission of arboviruses among Bornean orangutans. Am J Trop Med Hyg. 2001;64:310-6.

50. Musso D, Nhan T, Robin E, Roche C, Bierlaire D, Zisou K, et al. Potential for Zika virus transmission through blood transfusion demonstrated during an outbreak in French Polynesia, November 2013 to February 2014. Euro Surveill. 2014;19:20761.

51. Musso D, Roche C, Robin E, Nhan T, Teissier A, Cao-Lormeau VM. Potential sexual transmission of Zika virus. Emerg Infect Dis. 2015;21:359-61. doi:10.3201/eid2102.141363.

52. Besnard M, Lastere S, Teissier A, Cao-Lormeau V, Musso D. Evidence of perinatal transmission of Zika virus, French Polynesia, December 2013 and February 2014. Euro Surveill. 2014;19:20751.

53. Petersen EE, Erin Staples J, Meaney-Delman Dana, Fischer Marc, Ellington Sascha R, Callaghan William M, et al. Interim guidelines for pregnant women during a Zika virus outbreak-United States, 2016. MMWR Morb Mortal Wkly Rep. 2016;65:30-3.

54. Barthel A, Gourinat A-C, Cazorla C, Joubert C, DupontRouzeyrol M, Descloux E. Breast milk as a possible route of vertical transmission of dengue virus? Clin Infect Dis. 2013;57:415-7.

55. Hinckley AF, O'Leary DR, Hayes EB. Transmission of West Nile virus through human breast milk seems to be rare. Pediatrics. 2007;119:e666-71.

56. Chen LH, Wilson ME. Transmission of dengue virus without a mosquito vector: nosocomial mucocutaneous transmission and other routes of transmission. Clin Infect Dis. 2004;39:e56-60.

57. Leung GH, Baird RW, Druce J, Anstey NM. Zika virus infection in Australia following a monkey bite in Indonesia. Southeast Asian J Trop Med Public Health. 2015;46:460-4.

58. Gourinat AC, O'Connor O, Calvez E, Goarant C, DupontRouzeyrol M. Detection of Zika virus in urine. Emerg Infect Dis. 2015;21:84-6. doi:10.3201/eid2101.140894.

59. Musso D, Roche C, Nhan TX, Robin E, Teissier A, CaoLormeau VM. Detection of Zika virus in saliva. J Clin Virol Off Publ Pan Am Soc Clin Virol. 2015;68:53-5. doi:10.1016/j. jcv.2015.04.021.

60. Majumder MS, Cohn E, Fish D, Brownstein JS. Estimating a feasible serial interval range for Zika fever. Bull World Health Organ. 2016. doi:10.2471/BLT.16.171009.

61. Ahmad SS, Amin TN, Ustianowski A. Zika virus: management of infection and risk. BMJ. 2016;352:11062. doi:10.1136/bmj. i1062.

62. Brasil P, Pereira JP Jr, Raja Gabaglia C, Damasceno L, Wakimoto M, Ribeiro Nogueira RM, et al. Zika virus infection in pregnant women in Rio de Janeiro-preliminary report. N Engl J Med. 2016; d doi:10.1056/NEJMoa1602412.

63. Petersen LR, Jamieson DJ, Powers AM, Honein MA. Zika virus. N Engl J Med. 2016;374:1552-63. doi:10.1056/NEJMra1602113.

64. Chen LH. Zika virus infection in a Massachusetts resident after travel to Costa Rica: a case report. Ann Intern Med. 2016;164:574-6.

65. Tappe D, Nachtigall S, Kapaun A, Schnitzler P, Gunther S, Schmidt-Chanasit J. Acute Zika virus infection after travel to Malaysian Borneo, September 2014. Emerg Infect Dis. 2015;21:911-3. doi:10.3201/eid2105.141960.

66. Karimi O, Goorhuis A, Schinkel J, Codrington J, Vreden SG, Vermaat JS, et al. Thrombocytopenia and subcutaneous bleedings in a patient with Zika virus infection. Lancet. 2016;387:939-40. doi:10.1016/S0140-6736(16)00502-X.

67. Ingrid Rabe. Zika virus-what clinicians need to know? Centers for Disease Control and Prevention. 2016. https://emergency. cdc.gov/coca/ppt/2016/01_26_16_zika.pdf. Accessed 30 June 2016.

68. Oliveira Melo AS, Malinger G, Ximenes R, Szejnfeld PO, Alves Sampaio S, Bispo de Filippis AM. Zika virus intrauterine infection causes fetal brain abnormality and microcephaly: tip of the iceberg? Ultrasound Obstet Gynecol Off J Int Soc Ultrasound Obstet Gynecol. 2016;47:6-7. doi:10.1002/uog.15831.

69. Fleming-Dutra KE, Nelson JM, Fischer M, Staples JE, Karwowski MP, Mead P, et al. Update: interim guidelines for health care providers caring for infants and children with possible Zika virus infection-United States, February 2016. MMWR Morb Mortal Wkly Rep. 2016;65:182-7. doi:10.15585/mmwr. mm6507e1.

70. Waggoner JJ, Pinsky BA. Zika virus: diagnostics for an emerging pandemic threat. J Clin Microbiol. 2016;54:860-7. doi:10.1128/JCM.00279-16.

71. Martines RB. Notes from the field: evidence of Zika virus infection in brain and placental tissues from two congenitally infected newborns and two fetal losses-Brazil, 2015. MMWR Morb Mortal Wkly Rep. 2016;65. doi:10.15585/mmwr.mm6506e1.

72. Calvet G, Aguiar RS, Melo AS, Sampaio SA, de Filippis I, Fabri $\mathrm{A}$, et al. Detection and sequencing of Zika virus from amniotic fluid of fetuses with microcephaly in Brazil: a case study. Lancet Infect Dis. 2016;. doi:10.1016/S1473-3099(16)00095-5.

73. World Health Organization. Epidemiological alert: neurological syndrome, congenital malformations, and Zika virus infection: implications for public health in the Americas. 2015. http://www.paho.org/hq/index.php?option=com_docman $\&$ task $=$ doc_download\&Itemid $=270 \&$ gid $=32405 \& l a n g=e n$. Accessed 8 Aug 2016.

74. Schuler-Faccini L. Possible association between Zika virus infection and microcephaly-Brazil, 2015. MMWR Morb Mortal Wkly Rep. 2016;65. doi:10.15585/mmwr.mm6503e2.

75. Silasi M, Cardenas I, Kwon JY, Racicot K, Aldo P, Mor G. Viral infections during pregnancy. Am J Reprod Immunol. 2015;73:199-213. doi:10.1111/aji.12355.

76. Calvet G, Aguiar RS, Melo AS, Sampaio SA, de Filippis I, Fabri A, et al. Detection and sequencing of Zika virus from amniotic fluid of fetuses with microcephaly in Brazil: a case study. Lancet Infect Dis. 2016;16:653-60. doi:10.1016/ S1473-3099(16)00095-5.

77. Bearcroft WG. Zika virus infection experimentally induced in a human volunteer. Trans R Soc Trop Med Hyg. 1956;50:442-8.

78. de Melo Freire CC, Iamarino A, de Lima Neto DF, de Andrade Zanotto PM. Spread of the pandemic Zika virus lineage is associated with NS1 codon usage adaptation in humans. BioRxiv. 2015. doi:10.1101/032839.

79. Garcez PP, Loiola EC, Madeiro da Costa R, Higa LM, Trindade P, Delvecchio R, et al. Zika virus impairs growth in human neurospheres and brain organoids. Science. 2016;352:816-8. doi:10.1126/science.aaf6116.

80. Qian X, Nguyen HN, Song MM, Hadiono C, Ogden SC, Hammack $\mathrm{C}$, et al. Brain-region-specific organoids using mini-bioreactors for modeling ZIKV exposure. Cell. 2016;165:1238-54.

81. World Health Organizaton. Fact sheet: Microcephaly. 2016. http://www.who.int/mediacentre/factsheets/microcephaly/en/. Accessed 16 July 2016. 2016.

82. Cugola FR, Fernandes IR, Russo FB, Freitas BC, Dias JL, Guimaraes KP, et al. The Brazilian Zika virus strain causes birth defects in experimental models. Nature. 2016;534:267-71. doi:10.1038/nature 18296.

83. Li C, Xu D, Ye Q, Hong S, Jiang Y, Liu X, et al. Zika virus disrupts neural progenitor development and leads to microcephaly in mice. Cell Stem Cell. 2016;19:120-6. doi:10.1016/j. stem.2016.04.017. 
84. Miner JJ, Cao B, Govero J, Smith AM, Fernandez E, Cabrera $\mathrm{OH}$, et al. Zika virus infection during pregnancy in mice causes placental damage and fetal demise. Cell. 2016;165:1081-91. doi:10.1016/j.cell.2016.05.008.

85. Hofer U. Viral pathogenesis: tracing the steps of Zika virus. Nat Rev Microbiol. 2016;14:401. doi:10.1038/nrmicro.2016.80.

86. Cao-Lormeau VM, Blake A, Mons S, Lastere S, Roche C, Vanhomwegen J, et al. Guillain-Barre syndrome outbreak associated with Zika virus infection in French Polynesia: a case-control study. Lancet. 2016;387:1531-9. doi:10.1016/ S0140-6736(16)00562-6.

87. Li MI, Wong PS, Ng LC, Tan CH. Oral susceptibility of Singapore Aedes (Stegomyia) aegypti (Linnaeus) to Zika virus. PLoS Negl Trop Dis. 2012;6:e1792. doi:10.1371/journal. pntd.0001792.

88. Wong PS, Li MZ, Chong CS, Ng LC, Tan CH. Aedes (Stegomyia) albopictus (Skuse): a potential vector of Zika virus in Singapore. PLoS Negl Trop Dis. 2013;7:e2348. doi:10.1371/ journal.pntd.0002348.

89. Hamel R, Dejarnac O, Wichit S, Ekchariyawat P, Neyret A, Luplertlop $\mathrm{N}$, et al. Biology of Zika virus infection in human skin cells. J Virol. 2015;89:8880-96. doi:10.1128/ JVI.00354-15.

90. Carneiro LA, Travassos LH. Autophagy and viral diseases transmitted by Aedes aegypti and Aedes albopictus. Microb Infect/Inst Pasteur. 2016;18:169-71. doi:10.1016/j. micinf.2015.12.006.

91. Chan JF, Choi GK, Yip CC, Cheng VC, Yuen KY. Zika fever and congenital Zika syndrome: an unexpected emerging arboviral disease. J Infect. 2016;72:507-24. doi:10.1016/j. jinf.2016.02.011.

92. European Centre for Disease Prevention and Control. Interim guidance for healthcare providers and Zika virus laboratory diagnosis. ECDC, Stockholm. 2016. http://ecdc.europa.eu/en/ publications/Publications/zika-virus-guidance-healthcare-providers-and-laboratory-diagnosis.pdf. Accessed 10 July 2016.

93. Barzon L, Pacenti M, Franchin E, Pagni S, Martello T, Cattai $\mathrm{M}$, et al. Excretion of West Nile virus in urine during acute infection. J Infect Dis. 2013;208:1086-92. doi:10.1093/infdis/ jit290.
94. Hirayama T, Mizuno Y, Takeshita N, Kotaki A, Tajima S, Omatsu T, et al. Detection of dengue virus genome in urine by real-time reverse transcriptase PCR: a laboratory diagnostic method useful after disappearance of the genome in serum. J Clin Microbiol. 2012;50:2047-52. doi:10.1128/JCM.06557-11.

95. Shinohara K, Kutsuna S, Takasaki T, Moi ML, Ikeda M, Kotaki A, et al. Zika fever imported from Thailand to Japan, and diagnosed by PCR in the urine. J Travel Med. 2016;23:tav011.

96. Campos RDM, Cirne-Santos C, Meira GL, Santos LL, de Meneses MD, Friedrich J, et al. Prolonged detection of Zika virus RNA in urine samples during the ongoing Zika virus epidemic in Brazil. J Clin Virol Off Publ Pan Am Soc Clin Virol. 2016;77:69-70.

97. Atkinson B, Hearn P, Afrough B, Lumley S, Carter D, Aarons EJ, et al. Detection of Zika virus in semen. Emerg Infect Dis. 2016;22:940. doi:10.3201/eid2205.160107.

98. Staples JE, Dziuban EJ, Fischer M, Cragan JD, Rasmussen $\mathrm{SA}$, Cannon MJ, et al. Interim guidelines for the evaluation and testing of infants with possible congenital Zika virus infection-United States, 2016. MMWR Morb Mortal Wkly Rep. 2016;65:63-7. doi:10.15585/mmwr.mm6503e3.

99. Hennessey M, Fischer M, Staples JE. Zika virus spreads to new areas-region of the Americas, May 2015-January 2016. Am J Transpl. 2016;16:1031-4.

100. Dyer O. Jamaica advises women to avoid pregnancy as Zika virus approaches. BMJ. 2016;352:i383.

101. Sabchareon A, Wallace D, Sirivichayakul C, Limkittikul K, Chanthavanich P, Suvannadabba S, et al. Protective efficacy of the recombinant, live-attenuated, CYD tetravalent dengue vaccine in Thai schoolchildren: a randomised, controlled phase 2b trial. Lancet. 2012;380:1559-67. doi:10.1016/ S0140-6736(12)61428-7.

102. Bennett JE, Dolin R, Blaser MJ. Principles and practice of infectious diseases. Amsterdam: Elsevier Health Sciences; 2014.

103. Ishikawa T, Yamanaka A, Konishi E. A review of successful flavivirus vaccines and the problems with those flaviviruses for which vaccines are not yet available. Vaccine. 2014;32:1326-37. 